\title{
O UM-E-OUTRA: OS CONTRÁRIOS EM UM CONTO DE GUIMARÃES ROSA
}

\author{
ZAMA CAIXETA NASCENTES \\ Especialista em Língua Portuguesa FFCL de Patos de \\ Minas-MG \\ Especializando em Filosofia Política - UFPR.
}

Resumo:

\begin{abstract}
No presente artigo analisamos o conto "Substância" de "Primeiras
Estórias". Nossa atenção concentra-se nos pares de contrários eu/outro, masculino/feminino, razão/emoção, repouso/movimento que no final do conto são harmonizados.
\end{abstract}

\begin{abstract}
A problemática dos contrários preocupou o homem desde seus primórdios. Assim, já a encontramos nos mitos primitivos, nos primeiros filósofos gregos, como em Heráclito, por exemplo. Modernamente, os contrários ocuparam a atenção de Hegel em sua dialética e a de Jung em sua psicologia, levando-o a voltar-se para a mitologia. Em nossa análise, por tanto, serão recorrentes as referências à mitologia, à filosofia e à psicologia junguiana.

O título do artigo é tomado de empréstimo ao próprio conto que ora consideramos. Propositalmente escolhemos este sintagma, "um-e-outra", já que nele temos dois pares de contrários: eu/outro, masculino/feminino que são harmonizados, formando assim uma só substância.
\end{abstract}

\section{INTRODUÇÃO}

Para nosso plano de atividade em regime de dedicação exclusiva ao CEFET-PR propusemonos a analisar a questão dos contrários na obra de Guimarães Rosa. Quando operamos esse recorte tínhamos como referência o conto "Substância" em que aquela questão é tematizada. Queríamos assim verificar se se tratava de uma ocorrência isolada naquele conto ou se aparecia em outras obras.

A temática dos opostos ocupa lugar nos vários ramos do conhecimento humano: mitologia, filosofia e ciência. Em nossa análise serão freqüentes as referências a tais ramos. No que concerne à ciência estaremos fazendo uso da psicologia junguiana que, além dos contrários, volta-se também para a mitologia.

Em "Substância" os contrários aparecem harmonizados ao final do conto. Os personagens transcenderam assim o nível imediato de uma realidade, superando a cisão dos opostos. Para falar deste outro estágio em que eles se encontram Guimarães Rosa lança mão de estruturas lingüísticas carregadas de paradoxos: "acontecia o não-fato", "em-si-juntos", "avançavam, parados". Em função disso abordaremos o problema dos limites da linguagem humana, insuficiente para falar de uma realidade que não a imediata, fenomênica. 
O presente artigo é resultado parcial daquele nosso plano de atividade, cuja duração prevista é de dois anos. Nossa pesquisa continuará após essa publicação. Não sabemos onde essa pesquisa nos levará. Afinal, pesquisar "é negócio perigoso" pois obriga-nos a rever sempre nossa heurística. Mas, ousamos correr o risco. Oxalá a confissão dessa ousadia ajude-os a compreenderem na justa medida o que se segue.

Finalizemos essa introdução com um soneto de Augusto dos Anjos cujo título é significativo para nosso trabalho:

\section{VÍTIMA DO DUALISMO}

Ser miserável dentre os miseráveis

- Carrego em minhas células sombrias

Antagonismos irreconciliáveis

E as mais opostas idiossincrasias!

Muito mais cedo do que o imagináveis

Eis-vos, minha alma, enfim, dada às bravias

Cóleras dos dualismos implacáveis

E à gula negra das antinomias

Psiquê biforme, o Céu e o Inferno absorvo...

Criação a um tempo escura e cor-de-rosa,

Feita dos mais variáveis elementos,

Ceva-se em minha carne, como um corvo,

A simultaneidade ultramonstruosa

De todos os contrastes famulentos! (1)

\section{O UM}

Sionésio é um solteiro fazendeiro cuja atividade econômica consiste no plantio de mandioca para o fabrico de farinha e polvilho. Para isso mantém vários empregados. Tal atividade tomaIhe todo o tempo:

\section{"...a vida não lhe deixava cortar pelo sono: era um espreguiçar-se ao adormecer, para poupar tempo no despertar." (PE - p.137) (2)}

Por essa razão não repara nas transformações por que passa Maria Exita, uma das suas empregadas.

"Prazer era ver, aberto, sob o fim do sol, o mandiocal de verdes mãos" (p. 138) e não as "incertas casas, onde lhe dessem, ao corpo, consolo: atendimento de repouso" (p.138). Embora possua uma "quase noiva" não é dado a visitas à mesma: mal chegava à fazenda dela "esporeava de volta".

Seus pensamentos estavam voltados só para o progresso de sua atividade econômica: 
até então rapaz dado e mandraças visagens, avançara-se com decisão de açoite a desmedirIhe o fabrico. Plantava à vasta os alqueires de mandiocal (...); chamava e pagava braço..." (PE p.137)

Se o avio da farinha se pelejava ainda rústico, em breve o poderia melhorar mediante muito, por máquinas, dobrar quantidades."(PE - p.138)

Assim absorto segue desconhecendo a contradição que é a vida humana, posto que não se introduzira em seus dias a antítese. Isso só acontece quando reconhece as transformações que se operaram em Maria Exita.

\section{A OUTRA}

"Para a azáfama de farinha e polvilho" Sionésio trouxera à fazenda, "por piedade", Maria Exita, "menina, feiosinha, magra, historiada de desgraças" (p.137). A vida pregressa da personagem é, de fato, um desgraçar desfiado:

"...a mãe, leviana, desaparecida de casa; um irmão, perverso, na cadeia, por atos de morte; 0 outro, igual feroz, foragido, ao acaso de nenhuma parte; o pai, razoável bom-homem, delatado com a lepra, e prosseguido, decerto, para sempre, para um lazareto. Restassem-Ihe nem afastados parentes..." (PE - p.138)

Maria Exita cresce, transforma-se e Sionésio apaixona-se por ela. Os dois terminam juntos, a empregada, "feiosinha", junta-se ao patrão. Vemos aqui o diálogo travado por Guimarães Rosa com o conto de fadas "A gata borralheira". A hipótese de uma intertextualidade torna-se mais plausível quando lemos o que se segue:

"Deram-Ihe, porém, ingrato serviço, de todos o pior: o de quebrar à mão, o polvilho, nas lajes." (PE -p.138)

Todavia, suspendamos aqui a hipótese. Que outros a considerem em suas exegeses roseanas. A nós interessam os contrários.

O que nos chama a atenção no início de "Substância" é a inusitada biografia de Maria Exita. Abandonada, órfã - posto que a mãe é desaparecida e o pai "prosseguido para um lazareto"sem apoio de irmãos. E, ao contrário da gata borralheira, desamparada também pela madrinha "que pelo lugar apenas passara, agora ninguém sabendo se e onde vivia". (p.138) Por apresentar tais traços biográficos Maria Exita encarna em si os atributos do mito do "deuscriança", presente na mitologia primitiva. Abandonemos (também nós!) Maria Exita para embrenharmos pelos caminhos da mitologia: 
surrounded by, and evoke, an aura of fairy-tale. Not for any unaccountable essentiall irrational reason, but rather because of their clearly visible and everrecurring characteristics. The child-god is usually an abandoned foundling. (...) Sometimes the father is the child's enemy (...)or he may be merely absent". (3)

Maria Exita não é uma divindade. O que aqui assinalamos é a plausibilidade de um paralelo entre sua infância, "historiada de desgraças", eo mito do deus-criança. Este paralelo tem uma função heurística assaz significativa, pois possibilita-nos antever o papel que Maria Exita irá desempenhar na vida de Sionésio: ultrapassar a realidade dada, marcada pelos opostos e atingir uma outra realidade que, segundo o misticismo oriental, sustenta e unifica todas as coisas. No dizer de Jung:

"One of the essential features of the child-motif is its futurity. The child is potential future. Hence the occurrence of the child-motif in the psychology of the individual signifies as a rule an anticipation of future developments (...) In the individuation process, it anticipates the figure that comes from the synthesis of conscious and unconscious elements in the personality. It is therefore a uniting symbol which unites the opposites; a mediator, bringer of healing, that is, one who makes whole." (Destacado no original)(4)

Arquetipicamente, portanto, a criança antecipa síntese dos opostos, dentre elas a dos elementos conscientes e inconscientes. Ora, Maria Exita atuará em Sionésio como o "child-archetype" atua no indivíduo ao longo do seu processo de individuação.

A luminosidade domina todo o conto "Substância": a fazenda de Sionésio está tomada pela "azáfama - de farinha e polvilho", essencialmente brancos; a descoberta por Sionésio da transformação de Maria Exita de "menina feiosinha, magra" para embelezada moça, "ela, flor", se dá em uma das festas de maio, "mês de orvalho, da Virgem, de claridades no campo" (p.137). Sua visita a ela durante o trabalho se dá nas seguintes circunstâncias:

\footnotetext{
"Demorara para ir vê-la - só no pino do meio-dia de um sol do qual o passarinho fugiu. Ela (...) esperava que trouxessem outros pesados, duros blocos de polvilho. Alvíssimo, era horrível aquilo. (...) os olhos da pessoa tendo de ficar miudinho fechados (...) ante a implacável alvura, o sol em cima. $O$ dia inteiro, o ar parava levantado, aos tremeluzes, a gente se perdendo por um negrume do horizonte, para temperar a intensidade brilhante, branca..." (PE - p.138-9)
}

Como se vê, a luminosidade impera. Esse império no conto explica (ou é explicado por?) a 
utilização do adjetivo "alvo" e suas variações: alva (p.137), alvíssimo (p.138), alvura (p.139). Além disso aparecem os neologismos por verbalização, alvava (p. 142), e substantivação, alvor (p. 142). Da mesma forma temos "claro", "sol", "solsim", "refulgir", "luz", "claridade", "branco", que iluminam todo o conto, à semelhança da "iluminação mística", metáfora empregada pelo misticismo oriental para designar o estágio alcançado pela contemplação e meditação no qual os opostos são harmonizados e a realidade surge como uma unidade.

O elemento luz assume significações outras quando constatamos que Maria Exita não só é envolvida pela luminosidade (o que não seria um predicado exclusivamente seu, posto que o é também de Sionésio) mas também é luminosa:

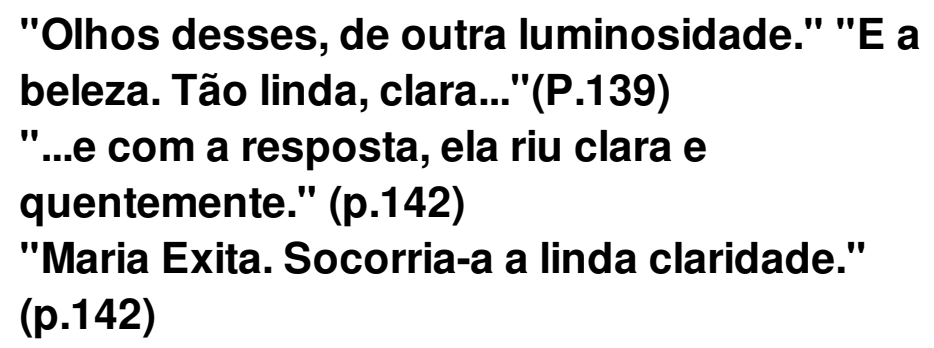

Esse dado da personagem evoca a estrutura das teofanias presentes nas tradições religiosas de vários povos nas quais a manifestação do divino, do sagrado, se dá sempre em meio a uma luminosidade. Pensemos, por exemplo, na tradição judaico-cristã: Javé no Sinai, Cristo no Tabor, Maria em Fátima. A luminosidade é assim um "morfema" da sintaxe simbólica do homem para expressar sua experiência do e com o sagrado. Em "Substância" isso não implica afirmar a divindade de Maria Exita mas sim vislumbrar nela a potencialidade para superação dos opostos. Essa potencialidade é realçada pela áura de pureza que a envolve:

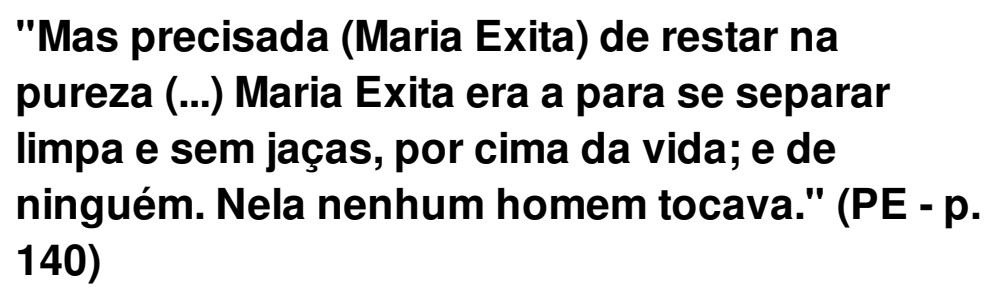

\section{O UM-E-OUTRA}

Após constatar que "estava amando mais ou menos" (p.140), Sionésio, vencidos todos os receios que $o$ assaltavam, declara-se a Maria Exita:
"_Você tem vontade de confirmar o rumo de sua vida? (...)Você, Maria, quererá, a gente, nós dois, nunca precisar de se separar? Você, comigo, vem e vai?" (PE - p.142)

Essas palavras de Sionésio evocam as pronunciadas por Soropita em "Dão-Lalalão", no momento também de declaração à amada Doralda: 
O paralelo entre "Substância" e "Dão-Lalalão" encontra-se também na resposta das mulheres:

\author{
"Ela tinha respondido:_'Vou demais. Desatou \\ um sorriso."(PE - p. 142)
}

"Doralda, a mulher mais singular. _'Pois quero.

Vou demais.'_ela respondeu num vivo de pronta..." (NS - p. 64)

Singularidade de Doralda e Maria Exita; solidão de Soropita e Sionésio bem como declarações amorosas semelhantes; identidade na resposta das mulheres; superação da oposição masculino/feminino numa alusão à temática mítica da androginia (presente, dentre outras, na seguinte fala de Doralda: "Bem, eu acho que só ficava sossegada de tu nunca me deixar, era se eu pudesse estar grudada, de carnes, calor e sangue, costurados, nós dois juntos...' (NS - p.80): eis aí algumas semelhanças entre "Substância" e "Dão-Lalalão". Extrapola nosso propósito no presente artigo operar um estudo comparativo entre os dois textos. Em nossas atividades no CEFET-PR investigaremos sobretudo a última.

Será a anuência de Maria Exita à proposta de Sionésio que provocará o desfecho do conto no qual temos a superação da realidade imediata, cindida pelos opostos. Nossa análise atinge assim o ponto central. Transcrevemos, para tanto, o referido desfecho:

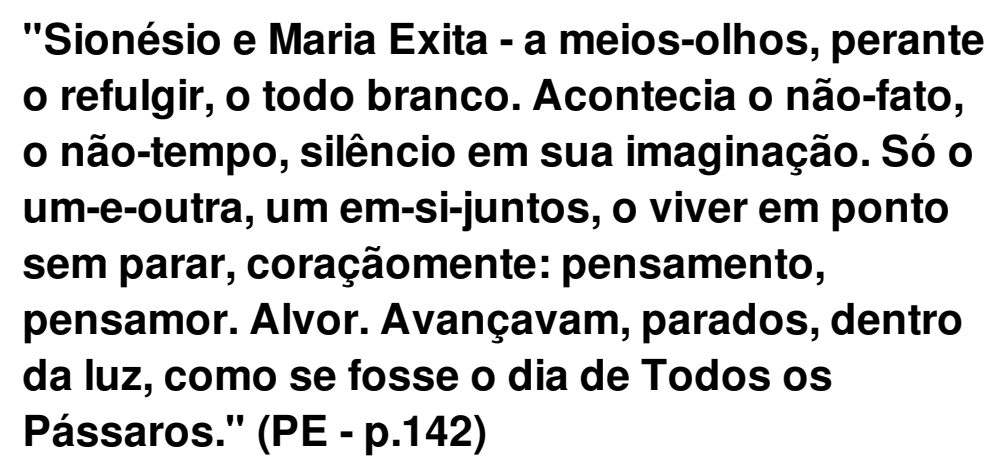

Como assinalamos anteriormente, "Substância" é um alvor de claridades refulgentes. No final do conto esse fenômeno luminoso atinge seu clímax: "refulgir", "o todo branco", "alvor", "luz". Porque os personagens estão em pleno meio-dia de um mês de maio, mês de "claridades no campo", em frente a uma mesa de pedra cheia de alvos brancos blocos de polvilhos, poder-se-ia considerar as refulgências como um mero dado do mundo exterior, uma simples descrição do espaço. Desse modo, elas não teriam significação nenhuma outra. Não pensamos assim. $O$ momento vivido pelos personagens converte a luminosidade em símbolo, metáfora, numa tentativa do autor de descrever o indescritível: o novo plano em que se encontram os personagens, inacessível à linguagem tradicional, que tem sua aplicabilidade circunscrita ao mundo fenomênico.

Antes de passarmos à análise dos pares de opostos que aqui são harmonizados, apontando assim para a nova esfera em que Sionésio e Maria Exita ingressaram, consideremos outro dado que também aponta para esse ingresso: o não-tempo. 


\section{Guimarães Rosa (AP - p.25) (6)}

Mesmo o senso comun afirma que o tempo constitui um limite da condição humana. Ao poder inexorável do tempo não escapamos, a não ser, no dizer de Marcuse, quando recordamos.

A mitologia também considera o tempo como inerente à condição humana: o homem enquanto tal, sexuado, mortal, cultural, surge a partir do momento em que a temporalidade é introduzida no cosmo (sucessões: dia/noite, estações do ano, ciclo anual). 0s mitos cosmogônicos narram esse irromper da temporalidade e os ritos constituem uma tentativa do homem primitivo de retornar àquela "unidade primordial", anterior à temporalidade, transcendendo-a, portanto. Também na filosofia o tempo se constitui objeto de investigação. Para ilustrar isso consideraremos aqui a filosofia crítica de Immanuel Kant.

Para Kant o tempo também é inerente à condição humana. Ele "é a condição formal 'a priori' de todos os fenômenos em geral" (Crítica da Razão Pura, § 6). Em termos psicológicos: o tempo faz parte do nosso aparelho mental que nos possibilita perceber os fenômenos (tanto do mundo exterior quanto do interior) como encadeados numa sucessão ou numa simultaneidade. Mais ainda, é o tempo que permite a constituição dos próprios fenômenos. O tempo não é algo exterior a nós, ele está em nós e por isso percebemos as coisas simultânea ou sucessivamente. Disso se segue que o homem jamais pode libertar-se do império da temporalidade já que o tempo radica-se na sua própria constituição ontológica. Para além do tempo está a "coisa-em-si" à qual não temos acesso. Já que o tempo é constitutivo do nosso modo de ser, percebemos sempre as coisas no tempo; por isso a coisa-em-si (nôumeno, na terminologia kantiana) permanece inacessível e incognoscível.

Da mesma forma o misticismo oriental afirma que o tempo é constitutivo da condição humana. Como a filosofia kantiana, a sabedoria oriental insiste em dizer que a realidade "em-si" não é constituída de temporalidade: faz parte do nosso modo de perceber o mundo e a realidade. Diferentemente da filosofia kantiana, o misticismo oriental sustenta a possibilidade de, mediante a contemplação e meditação, transcender a sucessão temporal e ingressar naquela realidade última atemporal: dá-se então a iluminação mística:

"Neste mundo espiritual não existem divisões do
tempo, como o passado, o presente e o futuro; pois
tais divisões contraíram-se num único momento do
presente, onde a vida palpita em seu verdadeiro
sentido (...) Passado e futuro são trazidos até esse
momento presente da iluminação e esse momento
presente não é algo que permanece parado com
tudo aquilo que contém, pois, incessantemente, ele
se move." (7)

Portanto, quer na mitologia, quer na filosofia kantiana, quer na sabedoria oriental o tempo é inerente à condição humana. Ritos, para a primeira, iluminação mística, para a terceira, possibilitam ao homem ultrapassá-lo. Já para a segunda isso é impossível: ainda que a coisaem-si possa ser pensada, embora não conhecida, isto não implica, por parte do sujeito pensante, uma superação do tempo. 
eles se dá o não-tempo deles não se pode mais dizer "situação", "momento", "agora" já que tais vocábulos trazem em si a categoria tempo. Quer tenham atingido a unidade originária dos mitos cosmogônicos, quer tenham atingido o mundo espiritual do misticismo oriental, o certo é que transcenderam o mundo fenomênico, submetido à necessidade, ao mecanicismo, à causalidade e à inexorabilidade do tempo. Por isso a linguagem tradicional, plasmada nesse mundo, já não se presta mais à narração do que lhes acontece. Isto explica o paradoxo do sintagma "acontecia o não-fato, o não-tempo" (e também o fim do conto?). Com efeito, a transitividade de "acontecer" postula um fato qualquer, não um não-fato. Logicamente teríamos que cambiar ou o verbo ou o complemento. Da mesma forma "não-tempo": ele não é, logo, não pode acontecer; e o acontecer implica tempo no qual se dê a transformação, mediante a qual novas determinações são acrescentadas a um sujeito. Paradoxo? Sim, se quisermos aplicar ao "estado" em que Sionésio e Maria Exita se encontram a lógica da linguagem convencional, temporalizada. Estamos aqui diante dos limites da linguagem humana, assaz circunscrita ao mundo fenomênico. Semelhante problema enfrenta o homem ao tentar comunicar sua experiência com o sagrado. Daí a recorrência dos símbolos na linguagem religiosa. Também o misticismo oriental: como falar de uma realidade última, em que os opostos se unen, utilizando-se de uma linguagem presa à percepção sensorial, à cisão espacial (direito/esquerdo, em cima/embaixo) e temporal (antes/depois, presente/passado/futuro)? Daí a recorrência do paradoxo na literatura sagrada do Oriente, como por exemplo os " Koans, enigmas absurdos utilizados pelos mestres Zen na transmissão de seus ensinamentos" (CAPRA, op. cit. p. 41), cuja finalidade é exatamente levar o discípulo a desconfiar da linguagem lógica, discursiva; do raciocícinio enfim. Aliás, o próprio Guimarães Rosa afirma textualmente em "Estas Estórias": "o mais fundo de meus pensamentos nem entende as minhas palavras", referindo-se assim a essa limitação da linguagem humana.

Considerado assim o "não-tempo" , voltemo-nos, finalmente, para os contrários: "um-e-outra", "em-si-juntos", "coraçãomente, pensamor", "avançavam, parados".

\section{"O um-e-outra":}

Como dissemos no sumário deste artigo, temos neste substantivo criado por Guimarães Rosa a junção de dois pares de opostos: eu/outro e masculino/feminino. Comecemos pelo primeiro.

Hegel em sua Fenomenologia do Espírito nos fornece elementos para a compreensão da oposição eu/outro (identidade/alteridade) quando aborda o processo pelo qual a consciência atinge a autoconsciência. Evitaremos aqui a hermética terminologia hegeliana.

A consciência tem consciência do mundo, não de si. Para tal precisa de uma outra consciência a fim de que ela se reconheça como consciência. Sem esta consciência $B$ a consciência $A$ não se reconheceria como consciência. Da mesma forma a consciência B. Ora, temos assim o confronto de duas consciências no qual, paradoxalmente, uma quer dominar a outra (como fazem com os objetos) mas não o pode fazer pois se assim proceder estará destruindo aquela consciência que é necessária à sua autoconsciência.

Dito de modo mais leigo: eu só sou eu (identidade) porque há o outro (alteridade) ao qual me oponho. Minha identidade se constrói no confronto com a alteridade. A significação dos termos (eu/outro, identidade/alteridade) é dada pela relação de oposição que há entre eles. Portanto, se desaparece um dos termos, o outro não terá razão de ser posto que ele é enquanto mantém aquela relação. Se eu fosse o único no universo eu não seria eu, pois não havendo o outro não faz sentido o eu. Mas este outro, tão necessário à minha identidade, é também uma ameaça $a$ 
ela posto que busca dominar-me, reificar-me (pensemos em nossos relacionamentos humanos...) anulando-me, enfim.

Em "Substância" não temos esse paradoxo existencial. Ao criar o substantivo "um-e-outra" Guimarães Rosa harmoniza os pares de opostos sem que isso implique anulação das partes (da mesma forma que na dialética hegeliana a síntese se dá preservando-se a especificidade da tese e da antítese). Sionésio e Maria Exita experimentam assim um estágio em que os opostos não são realidades diferentes mas sim aspectos diferentes de uma mesma realidade. Alcançar essa "realidade última" em que se dá a unidade dos opostos é o objetivo do misticismo oriental. A cisão está não na realidade mas em nosso intelecto que a capta. Portanto, só ao transcender a oposição estaremos entrando em contato com a realidade tal qual ela é, o que é inviável pois ao fazermos isso deixaremos nossa condição humana já que somos, ontologicamente, marcados por aquela cisão e oposição. Com Sionésio e Maria Exita eu/outro, identidade/alteridade se harmonizaram: são uma substância. O mesmo se dá com masculino/feminino.

É à mitologia que vamos recorrer para entendermos aqui o que seria essa superação da divisão masculino/feminino.

Já nos referimos aqui, ao tratarmos do tempo, aos mitos cosmogônicos (que narram a gênese do cosmo). Neles encontramos referências à unidade originária na qual masculino e feminino estavam juntos. É o motivo andrógino:

"Os mitos, efetivamente, narram não apenas a origem do mundo, dos animais, das plantas e dos homens, mas também de todos os acontecimentos primordiais em conseqüência dos quais o homem se converteu no que hoje é - um ser mortal, sexuado, organizado em sociedade..." (8)

Portanto, nos primórdios tínhamos o ser andrógino que não comportava a cisão masculino/feminino, constituindo-se assim numa totalidade.

Modernamente, a psicologia junguiana corroborou esta verdade expressa nos mitos ao demonstrar que o homem carrega em si estes dois aspectos, masculino/feminino. Ao primeiro correspondem comportamentos como a racionalidade, o pensamento analítico, a expansividade (iniciativa) enquanto que ao segundo correspondem a sensibilidade, o pensamento sintético, a receptividade. Jung deu àqueles aspectos o nome de ânimus e ânima, respectivamente. $A$ maturação psíquica do indivíduo dar-se-á a partir do momento em que o homem integrar à sua personalidade sua ânima, reconhecendo-a e acolhendo-a. Da mesma forma a mulher necessita integrar seu ânimus à sua personalidade, reconhecendo-o e aceitando-o. Caso contrário, o equilíbrio do indivíduo estará ameaçado, que permanecerá cindido psiquicamente, o que o distanciará ainda mais daquela unidade originária de que nos falam os mitos.

O misticismo oriental conseguiu uma harmonia entre os aspectos masculino e feminino. Já a cultura ocidental sempre privilegiou o primeiro em detrimento do segundo. .

Em "Substância" temos também essa harmonia. Guimarães Rosa a demonstra quando cria o substantivo um-e-outra composto de "um" (masculino) e "outra" (feminino). Tornou-se lugar comum falar dos neologismos roseanos. No caso específico de "um-e-outra" não cremos em um 
mero jogo de palavras. Trata-se, a nosso ver, de um esforço do autor para superar as limitações da linguagem convencional. Afinal, como falar de um "estado" em que a oposição masculino/feminino foi superada utilizando-se de uma língua em que as palavras são rigidamente categorizadas em masculino/feminino, nem sequer admitindo-se o neutro? Quando analisamos a questão do tempo apontamos para esse mesmo problema. Vimos que lá Guimarães Rosa opta por um paradoxo, "acontecia o não-fato, o não-tempo". Aqui construirá um sintagma que apresenta, além da determinação acima (junção do masculino e do feminino), uma outra, a saber: antepõe o artigo definido o a um substantivo criado a partir do artigo indefinido um. Ao efetivar tal operação lingüística o autor relativiza a oposição lógica - e também gramatical - entre definição e indefinição. Portanto, mais que proverbiais inusitados neologismos, o que o final de "Substância" nos revela é a universalidade da temática. Mais que regionalismo mineiro (fabricação de farinha e polvilho a partir da mandioca) o que temos é uma temática que remonta aos mitos cosmogônicos, à milenar sabedoria oriental; aos arquétipos, portanto, diríamos com Jung.

Ao considerarmos a vida pregressa de Maria Exita assinalamos a plausibilidade de um paralelo entre ela e o "child-motif" da mitologia e da psicologia junguiana. Em função disso já poderíamos antever em Maria Exita "a uniting simbol which unites the opposites", para repetirmos Jung. Ora, a anuência de Maria Exita à proposta de Sionésio ("_Você, Maria, quererá, a gente, nós dois, nunca precisar de se separar? Você, comigo, vem e vai?". "_Vou demais.' ") coloca-o num estágio (de elevação mística, no dizer da sabedoria oriental?) no qual até a percepção sensorial é abolida: "Ele nem viu." (P.142) Desse estágio participa também Maria Exita : "Nem viam a sombra de Nhatiaga, que quieta e calada, lá, no espaço do dia." Nesse estágio os opostos masculino/feminino se harmonizam, o que reforça a plausibilidade daquele paralelo.

\section{"Um em-si-juntos":}

Para compreendermos a oposição que aqui é vencida temos que recorrer à filosofia.

"Em-si" diz-se de algo isoladamente sem aplicar sobre esse algo a categoria relação, para falarmos kantianamente, ou o acidente, se quisermos falar escolasticamente.

Ora, o que temos em "Substância" é a quebra desse preceito metafísico mediante a introdução da relação no "em-si" através do vocábulo "juntos" que carrega consigo a idéia de relação. Em termos estritamente lógicos, "um em-si-juntos" fere o princípio da não-contradição. De fato, ou é "em-si", isoladamente, ou está "junto com" e aí não faz mais sentido falar de um "em-si". Portanto, estamos novamente diante de um paradoxo. Todavia, este paradoxo se desfaz quando nos lembramo de que Sionésio e Maria Exita ultrapassaram o mundo dos opostos, da realidade cindida pelos contrários. Estes são abstrações do nosso pensamento, não atributos da realidade em si alcançada pelos personagens. Por conseguinte, a eles não se aplica mais nossa lógica fundada na não-contradição aristotélica. Por isso é possível falar de um "em-si-juntos"

\section{"Coraçãomente, pensamor":}

"Quando o coração fala, não é conveniente que a razão faça objeções." 


\section{"O pensamento é um fútil pássaro. Toda razão é medíocre. \\ Viver é respirar. Pensar já é morrer." \\ Guimarães Rosa (AP - p.25)}

Diferentemente do que vínhamos fazendo com os outros opostos, não apresentaremos aqui considerações mitológicas ou filosóficas que explicitem a problemática da oposição, a saber: razão e emoção. Que cada um sonde sua história pessoal e saberá o que é esta oposição...

Em "Substância" esta oposição é duplamente enfocada, o que não acontece com as anteriores:

$$
\begin{aligned}
& \text { coraçãomente: coração + mente } \\
& \text { pensamor: pensamento + amor }
\end{aligned}
$$

Analisemos a primeira estrutura: coraçãomente.

Trata-se de um advérbio (=apaixonadamente, amorosamente) ou de um substantivo composto de coração + mente? As duas leituras são possíveis. Nossa análise incidirá na segunda. Todavia não descartamos a primeira. Longe de invalidar nossa análise ela a reforça: na realidade em que ingressaram Sionésio e Maria Exita há a unidade dos opostos, sem que eles se anulem. Portanto, pode-se falar em "coraçãomente" (advérbio) pois lá não cessou a emoção, apenas não se opõe à razão, estando em harmonia com ela. Ademais, o próprio fato de Guimarães Rosa criar um vocábulo que não está preso a uma única categoria gramatical, aponta para uma tentativa de superação da rigidez da linguagem tradicional, insuficiente para falar de uma realidade que ultrapassa nossa percepção imediata. Dito de outro modo: a categorização em substantivo ou advérbio não se aplica mais à narração do "não-fato" (há como narrá-lo?) que "acontece" entre Sionésio e Maria Exita mas só à factualidade e temporalidade da realidade imediata. Não obstante esta inaplicabilidade trataremos "coraçãomente" como um composto dos substantivos coração + mente.

A justaposição de "coração" e "mente" indica que em Sionésio e Maria Exita deu-se a harmonia entre razão e emoção. Este difícil equilíbiro (se não fosse seriam menores as dores por amor...) foi alcançado por eles. Para dialogarmos com Kundera: o coração pode falar e a razão apresentar objeções. Mas, se os dois estão em harmonia, que objeções poderia fazer a razão? Se assim o é, o que o coração terá a dizer? Se o tem, a razão o saberá antes que ele o diga, da mesma forma o coração "sentirá" as objeções antes que a razão as apresente! E, para respondermos a essas questões: não se pode nem mais falar em coração e razão separadamente, como entidades isoladas, posto que coração e mente são uma só substância: coraçãomente. (Situação muito diferente vive Teresinho em "A vela ao diabo" de Tutaméia: "Seu coração e cabeça pensavam coisas diversas." - P. 27)

A idéia de que razão/emoção harmonizaram-se é reforçada pelo neologismo "pensamor".

Morfologicamente temos a aglutinação de pensamento + amor, o que, semanticamente, equivale a coração + mente (Note-se que agora o aspecto racional está em primeiro plano. Não podemos exigir do autor uma simetria quando ele pretende nos falar de uma realidade em que tudo é unificado.) No plano da sintaxe poder-se-ia falar em amor enquanto objeto de pensa? 
Em "O grande samba disperso" de Ave, Palavra, temos uma construção semelhante:
"Amor perdido é amor que não foi achado: não- amor. Não o amor-mor, o mor amor. Mas falso amor, algum engano. $O$ falso amor é um biombo, o mor-amor é um ribombo." (AP - p. 26)

O que notamos aqui é a utilização de "mor" na qual o autor está a explorar as possibilidades morfológicas e fonológicas do vocábulo. Aparece ora no final (amor-mor), ora no começo (moramor), ora destacado, isolado (o mor amor). Fonologicamente o emprego de "mor" está para "amor" constituindo-se assim numa combinação rímica que acaba por musicalizar o trecho. Este trabalho com o estrato fônico fica evidente também na seleção dos substantivos "biombo" e "ribombo". Aqui, além da rima temos a própria sonoridade evocada por "ribombo".

Numa perspectiva diacrônica temos "mor" como resultante de "maior" via síncope; sendo portanto um adjetivo. É enquanto adjetivo que tal vocábulo é empregado no início de "Substância":

\section{"Pensava ele em maio, talvez. porque o mês mor - de orvalho, da Virgem, de claridade no campo." (PE, p.137)}

Ora, a questão que se coloca em nossa análise agora é esta: ao construir "pensamor" em "Substância", teria Guimarães Rosa utilizado "mor" como adjetivo, da mesma forma que em "amor-mor"? Se assim o for, "pensamor" não resulta de pensamento + amor e nossa análise queda invalidada?

A questão é complexa. Mais ainda se considerarmos que, ainda em Ave, Palavra, encontramos as seguintes construções

\section{"- Nunca nunca! \\ -Num canunca está você - canunca infausto." \\ "O caramujo no seu ujo, e o caranguejo, ejo." (p. 139)}

nas quais Guimarães Rosa está explorando as possibilidades morfo-fonológicas dos vocábulos. Exemplo disso encontramos também em "Retábulo de São Nunca" de Estas Estórias:

$$
\text { "Jamais, jamais, já mais..." (EE - p.206) }
$$

Insistimos que em "pensamor" temos pensamento + amor. A constatação de uma construção semelhante - "amor-mor" - em "O grande samba disperso" poderia invalidar nossa análise visto que permitiria afirmar que em "pensamor" não temos pensamento + amor mas sim pensa + mor, apontando assim para uma valorização do pensamento e não para uma harmonização entre pensamento e amor. Todavia, as construções "num canunca, canunca", "caramujo, ujo, caranguejo, ejo", "jamais, jamais, já mais" permitem ler "mor" de "amor-mor" não como adjetivação mas sim como um desmembramento para obtenção de efeitos sonoros. Ora, se 
assim o é, não se pode afirmar, categórica e dogmaticamente, que "pensamor" é constituído de pensa + mor. Assim sendo, pode-se também ler "pensamor" como formado de pensamento + amor. É nesta possibilidade que incide nossa análise. Todavia, estamos conscientes de que ela não é a única.

\title{
"Avançavam, parados":
}

\author{
Move. Não se move. \\ Está longe e está perto. \\ Está dentro de tudo isso, \\ Está fora de tudo isso." \\ (TF - p.120)
}

Temos aqui a junção dos contrários, repouso/movimento, que tanta especulação causaram nos primeiros filósofos gregos. Deixemo-los para nos preocuparmos apenas com Sionésio e Maria Exita.

\begin{abstract}
"Avançavam" implica movimento enquanto que "parados" implica repouso. Como entender o sintagma "avançavam, parados"?
\end{abstract}

Insistimos reiteradamente que os personagens de Guimarães Rosa já atingiram uma outra realidade na qual nossos binários conceitos intelectuais não penetram. Falar dessa realidade usando a linguagem convencional é um paradoxo e ele surgirá sempre que tentarmos descrever com essa linguagem uma situação que está para além da nossa experiência cotidiana, circunscrita à percepção sensorial e às regras do pensamento discursivo e analítico.

Portanto, é por estarem para além dessa experiência que Sionésio e Maria Exita podem "avançar, parados" já que a eles não se aplicam mais nossas categorias de tempo, espaço e movimento. Essa é uma tentativa de explicar o paradoxo. Outra, que também postulamos aqui, é a que se segue: Sionésio e Maria Exita não avançam parados, não sabemos se Ihes acontece algo, quanto menos o que Ihes acontece. O paradoxo é, portanto, o esforço do autor em penetrar uma realidade inacessível à nossa percepção e intelecção. Ao insistir em penetrá-la defronta-se sempre com o paradoxo.

CONCLUSÃO

\section{"...a síntese é qualquer coisa de terrível." Guimarães Rosa (10)}

Pares de opostos que se unificam, personagens que ultrapassam o nível da percepção sensorial e da aplicação das nossas categorias racionais: eis aí como Guimarães Rosa encerra "Substância". O irromper da questão dos contrários aponta para a universalidade da temática do conto, embora partindo de um dado regional como o é o cultivo da mandioca em Minas Gerais para fabricação de polvilho e farinha. Mitos cosmogônicos, pensamento filosófico, psicologia junguiana e misticismo oriental confirmam essa universalidade.

Estilisticamente, além dos característicos neologismos roseanos, temos a recorrência de paradoxos. Insistimos no fato de que em "Substância" eles não podem ser compreendidos numa perspectiva meramente formalística. Afinal, no dizer do próprio Guimarães, "toda a língua são 
rastros de velho mistério." (AP - p.72). Com isso não pretendemos erigir uma teoria que dê conta dos neologismos roseanos nem tampouco dizer que os paradoxos são marcas de seu estilo. Nunca é demais insistir que nossas teorizações aplicam-se somente a "Substância". Noutra oportunidade, à medida que executarmos nosso plano de atividades no CEFET-PR e constatarmos a aplicabilidade delas a outras obras, poderemos partilhá-las com a comunidade ledora de Guimarães Rosa.

Não tivemos a pretensão de esgotar o conto aqui analisado. Há aspectos que percebemos mas não mencionamos; outros há que nos escaparam.

"Antes falar bobagens, que calar besteiras", ensina-nos Brejeirinha de "Partida do audaz navegante" em Primeiras Estória. Calemo-nos portanto.

\section{NOTAS DE REFERÊNCIA}

1. ANJOS, Augusto dos: Obra Completa. Rio de Janeiro, Nova Aguilar, 1995, p. 340. Cf. também nesta edição a p. 260 em que o autor poetiza a mesma questão no soneto Contrastes.

2. ROSA, Guimarães: Primeiras Estórias. Rio de janeiro, Nova Fronteira, 1995, 25ª ed. Doravante apenas PE seguido da respectiva página.

3. KERENYI, C.: The primordial child in primordial times. In "Introduction to a Science of Mythology", London, Routledge \& Paul Ltd, p.38

4. JUNG, Carl G.: The psychology of the child-archetype. In "Introduction to a Science of Mythology", London, Routledge \& Paul Ltd, p. 115

5. ROSA, Guimarães: Noites do sertão. Rio de Janeiro, Nova Fronteira, 1984, $8^{\mathrm{a}}$ ed. p. 64 . Próximas referências: NS mais indicação de página.

6. ROSA, Guimarães: Ave, Palavra. Rio de Janeiro, José Olympio, 1978, $2^{\mathrm{a}}$ ed. p.25. Abreviado para AP com indicação de página.

7. CAPRA, Fritjof: $O$ tao da física: um paralelo entre a Física Moderna e o Misticismo Oriental. São Paulo, Cultrix. Doravante abreviado para TF.

8. ELIADE, Mircea: Mito e Realidade. São Paulo, Perspectiva, 1976, p.16

9. KUNDERA, Milan: A insustentável leveza do ser. Rio de Janeiro/São Paulo, Record, 1995,p.235.

10. ROSA, Guimarães: Sagarana, Rio de Janeiro/São Paulo, Record, 1995, p. 110

\section{BIBLIOGRAFIA}

CAPRA, Fritjof: $O$ tao da física: um paralelo entre a Física Moderna e o Misticismo Oriental. São Paulo. Cultrix. : O ponto de mutação. São Paulo. Cultrix.

CORNFORD, F. M.: Principium Sapientae: as origens do pensamento filosófico grego. Lisboa, Calouste Gulbenkian, $1989,3^{a}$ ed. ELIADE, Mircea: Mito e realidade. São Paulo, Perspectiva, 1972.

HEGEL, G. W. F.: Enciclopédia das ciências filosóficas em epítome, Lisboa, Edições 70, 1988, V. 1.

JUNG, Carl G. \& KERENYI, C.: Introduction to a Science of Mythology. London, Routledge \& Kegan Paul Ltda.

JUNG, Carl G.: O homem e seus símbolos. Rio de Janeiro, Nova Fronteira, s/d .

KANT, Immanuel: Crítica da razão pura. Lisboa, Fundação Calouste Gulbenkian, 1994, 3a ed.

KUNDERA, Milan: A insustentável leveza do ser. Rio de Janeiro/São Paulo, Record, 1995

MARCUSE, Herbert: Eros e civilização: uma interpretação filosófica do pensamento de Freud. São Paulo, Círculo do Livro, s/d.

ROSA, Guimarães:Primeiras estórias. Rio de Janeiro, Nova Fronteira, 1995, 28ª ed.

: Noites do sertão: Rio de Janeiro, Nova Fronteira, 1988, $8^{a}$ ed.

: Ave, palavra: Rio de Janeiro, José Olympio, 1978, 2ª ed.

: Estas estórias. Rio de Janeiro, José Olympio, 1976, 2ª ed.

: Sagarana: Rio de Janeiro/São Paulo, Record, 1995

: Manuelzão e Miguilin, Rio de Janeiro, José Olympio, 1976.

: Tutaméia, Rio de Janeiro, Nova Fronteira, 1985, 6ª ed. 
